\title{
Distribution of Plasmid Sequences in Avian and Mammalian Strains of Chlamydia psittaci
}

\author{
By MARGARET MCCLENAGHAN, ${ }^{1}$ JULIET R. HONEYCOMBE, ${ }^{2}$ \\ BOB J. BEVAN ${ }^{3}$ AND ALAN J. HERRING ${ }^{1}$ * \\ ${ }^{1}$ Moredun Research Institute, 408 Gilmerton Road, Edinburgh EH17 7JH, UK \\ ${ }^{2}$ Department of Biochemistry, University of Oxford, South Parks Road, Oxford OX1 3QU, UK \\ ${ }^{3}$ Central Veterinary Laboratory, Ministry of Agriculture, Fisheries and Food, Woodham Lane, \\ New Haw, Weybridge, Surrey KT15 3QU, UK
}

(Received 18 August 1987; revised 10 November 1987)

\begin{abstract}
Plasmid DNA from an avian strain of Chlamydia psittaci was purified and estimated to be $7.9 \mathrm{~kb}$ in size using restriction endonuclease analysis. A $5.9 \mathrm{~kb}$ fragment of this plasmid was cloned, mapped and used to screen a range of chlamydial strains. Hybridizing DNA was absent from ovine abortion and arthritis isolates and also from the Cal 10 strain but related sequences were detected in $C$. psittaci strains of feline pneumonitis, guinea-pig inclusion conjunctivitis, ovine conjunctivitis and $C$. trachomatis serovar L2. The plasmid DNA from the feline strain was shown to have a distinct restriction endonuclease profile. Similar plasmid sequences were detected in all avian isolates tested: thus the clone may have a useful diagnostic role for the detection of the pathogen in its natural host and in zoonotic episodes.
\end{abstract}

\section{INTRODUCTION}

The obligate intracellular parasite Chlamydia psittaci infects a variety of animal hosts, including man, and causes a wide spectrum of disease. There are no well-established typing systems for this pathogen but recent studies using microimmunofluorescence (Perez-Martinez \& Storz, 1985) and restriction endonuclease analysis of chlamydial DNA (McClenaghan et al., 1984) suggest that the species comprises many subtypes. In agarose gel analysis of undigested $C$. psittaci DNA from various strains, plasmid-like bands were observed in avian isolates but not in ovine strains (McClenaghan et al., 1984). Ethidium bromide staining in agarose gels is a relatively insensitive technique which would not detect very low copy numbers of plasmid or plasmid DNA integrated into the chromosome. It was therefore necessary to use hybridization as a more sensitive method of detection. Because of the difficulties in preparing workable amounts of $C$. psittaci plasmid, we cloned a plasmid fragment and used this in hybridization assays to screen a range of $C$. psittaci strains for the presence of similar sequences.

\section{METHODS}

Chlamydial strains. Some of the strains of C. psittaci used have been described previously (McClenaghan et al., 1984). They include eight isolates associated with outbreaks of ovine abortion, and one strain from a lamb with polyarthritis. In addition, a further recent ovine abortion isolate, 84/501, and a strain isolated from a case of ovine conjunctivitis, $\mathrm{CH}$ 1284, were examined. Purified preparations of elementary bodies of strains from guinea-pig inclusion conjunctivitis and feline pneumonitis were kindly supplied by Dr J. H. Pearce, Department of Microbiology, University of Birmingham, UK, and Dr S. J. Richmond, Department of Bacteriology and Virology, University of Manchester, UK, respectively. The L2 serovar of C. trachomatis LGV was a gift from Dr I.

Abbreviation: $\mathrm{CsCl} / \mathrm{EB}$, caesium chloride/ethidium bromide. 
Table 1. Avian isolates of C. psittaci

\begin{tabular}{|c|c|c|c|}
\hline $\begin{array}{c}\text { Isolate } \\
\text { designation }\end{array}$ & \multicolumn{2}{|c|}{ Source/passage level } & $\begin{array}{l}\text { Gel tra } \\
\text { in Fig. }\end{array}$ \\
\hline 352 & Duck/not known & & \\
\hline ISN 1021 & Collared dove $/ 7$ & & \\
\hline ISN 1057 & Collared dove $/ 4$ & & \\
\hline ISN 1316 & Budgerigar/4 & & \\
\hline ISN 1536 & Budgerigar/4 & & \\
\hline ISN 1670 & Budgerigar $/ 3$ & & \\
\hline ISN 1671 & Budgerigar $/ 4\}$ & & \\
\hline ISN 1528 & Parrot $/ 5\}$ Same hird & & \\
\hline ISN 1529 & Parrot $/ 4\}$ & & \\
\hline ISN 1585 & Parrot $/ 5$ & & 9 \\
\hline ISN 1263 & Parakeet $/ 6\}$ Same bird & & 10 \\
\hline ISN 1264 & Parakeet $/ 5\}$ Same oird & & 11 \\
\hline ISN 1812 & Cockatoo/3 & & 12 \\
\hline ISN 1813 & Java sparrow/2 & Imported at same time & 13 \\
\hline ISN 1814 & Munia (finch)/3 & from Java/Borneo & 14 \\
\hline ISN 1815 & Finch (pin-tailed parrot) $/ 2]$ & & 15 \\
\hline ISN 725 & Cockatiel/11 (plasmid donor & train) & \\
\hline ISN 741 & Wood pigeon/11 & & 1 \\
\hline
\end{tabular}

Smith, Department of Bacteriology, University of Edinburgh, UK. The avian isolates included in this study are described in Table 1 :

Culture and purification of elementary bodies. Methods used were described by McClenaghan et al. (1984). Briefly, chlamydial strains were cultured in BHK-21 cells treated with 5-iodo-2'-deoxyuridine, except for avian isolates ISN 1021 to 1815 listed in Table 1, which were cultured in L929 cells treated with emetine (Bevan \& Bracewell, 1986). Elementary bodies were purified by centrifugation through $30 \%$ (v/v) Urografin (Schering), followed by density gradient centrifugation (30-60\%, v/v Urografin). All avian strains were grown and purified in biohazard laboratories.

Preparation of chlamydial DNA. In most cases, total chlamydial DNA was extracted from purified elementary bodies by the method described by Wenman \& Lovett (1982). However, with avian isolates, DNA was prepared from elementary bodies produced by the sucrose cushion method (McClenaghan et al., 1984) or simply from infected cells.

Plasmid DNA was isolated by caesium chloride/ethidium bromide $(\mathrm{CsCl} / \mathrm{EB})$ density gradient centrifugation as described by Maniatis et al. (1982). The gradient fractions containing plasmid DNA were identified by agarose gel electrophoresis of small samples. Plasmid DNA for cloning was isolated by preparative gel electrophoresis; plasmid bands were excised from gels and the DNA was purified by electroelution, phenol extraction, ethanol precipitation and ion-exchange chromotography using an 'Elutip' mini-column (Schleicher and Schüll).

Gel analysis of DNA. Agarose gel analysis was done using standard techniques with either Tris/sodium phosphate buffer (36 mM-Tris, $30 \mathrm{~mm}$-sodium dihydrogen phosphate, 1 mM-EDTA, pH 7.6) or Tris/acetic acid buffer ( $40 \mathrm{mM}$-Tris, $20 \mathrm{mM}$-sodium acetate, $1 \mathrm{mM}$-EDTA, $\mathrm{pH} \mathrm{7.5)}$ ) for the preparative experiments.

Continuous $(7.5 \% \mathrm{w} / \mathrm{v})$ polyacrylamide gels were used to analyse small DNA digest fragments. These gels were silver-stained by the method described by Herring et al. (1982) except that with this buffer system, the initial washing time in $10 \%(\mathrm{v} / \mathrm{v})$ ethanol and $0.5 \%$ acetic acid was reduced to $10 \mathrm{~min}$ and the $0.01 \mathrm{M}$-silver nitrate wash to $20 \mathrm{~min}$.

Restriction endonuclease digests were done under the conditions recommended by the manufacturers (BRL and Northumbria Biologicals).

Hybridization conditions. Southern transfer was by the method described by Maniatis et al. (1982), and dot blot filters were prepared by loading 0.1 $\mathrm{gg}$ amounts of alkaline-denatured DNA using a BRL 'Hybridot' manifold.

Purified preparations of plasmid DNA or the insert from clone pAV-1 were labelled by nick-translation to a specific activity of $1-2 \times 10^{8}$ c.p.m. $\mu \mathrm{g}^{-1}$ (Rigby et al., 1977). Filter hybridization was done by using the methods described by Maniatis et al. (1982); filters were then washed twice in $1 \times \operatorname{SSC}(0.15 \mathrm{M}-\mathrm{NaCl}, 0.015 \mathrm{M}$-trisodium citrate, $\mathrm{pH} 7.0)$ with $0.1 \%(\mathrm{w} / \mathrm{v}) \mathrm{SDS}$ for $15 \mathrm{~min}$ at room temperature, followed by two washes in $0.1 \times \mathrm{SSC}$ in $0.1 \%$ (w/v) SDS at $42^{\circ} \mathrm{C}$.

Molecular cloning of chlamydial plasmid DNA. Cloning was by essentially standard methods (Maniatis et al., 1982) using the pUC9 vector (Yanisch-Perron et al., 1985) linearized at the HindIII site. Following dephosphorylation and ligation to HindIII-digested chlamydial plasmid DNA, ligated DNA was used to transform Escherichia coli strain JM83 made competent by the high-efficiency procedure of Hanahan et al. (1983). 
Transformants were selected on ampicillin plates containing X-Gal (5-bromo-4-chloro-3-indolyl $\beta$-Dgalactopyranoside) and IPTG (isopropyl $\beta$-D-thiogalactopyranoside), and screened by the method of Grunstein \& Hogness (1975) using nick-translated chlamydial plasmid. Recombinant plasmid DNA was purified from the clone pAV-1 by the alkaline-lysis method (Maniatis et al., 1982) followed by $\mathrm{CsCl} / \mathrm{EB}$ density gradient centrifugation.

Restriction endonuclease site mapping. Mapping was achieved by conventional double digest techniques, and by using plasmid insert cleaved with $\mathrm{NciI}$ after end-labelling the HindIII sticky ends with the Klenow fragment of DNA polymerase I (Maniatis et al., 1982). The large NciI fragment was purified by rate zonal density gradient centrifugation (Raafat El-Gewely \& Helling, 1980) and mapped by partial digestion (Smith \& Birnsteil, 1976).

\section{RESULTS}

Agarose gel analysis of undigested DNA preparations from avian strains of $C$. psittaci derived from cockatiel, pigeon and duck sources all showed extrachromosomal plasmid bands. Analysis of the total undigested DNA of the cockatiel strain 725 on $\mathrm{CsCl} / \mathrm{EB}$ density gradients confirmed that these bands consisted of covalently closed circular DNA, since they were found at a higher density than the chromosomal DNA. The constraints imposed by the containment facilities limited the size of avian cultures produced for analysis. Therefore only small amounts (10-50 ng) of purified plasmid were available for restriction endonuclease studies to identify a suitable cleavage site with which to clone plasmid sequences. The largest fragment identified was a HindIII fragment of approximately $6 \mathrm{~kb}$. However, PAGE of HindIII digests revealed that the enzyme also produced four smaller fragments as shown in Fig. 1 (track 1). Accordingly, a HindIII digest was ligated to HindIII-linearized pUC9 and the mixture used to transform competent $E$. coli cells. Several colonies were identified by screening with nick-translated plasmid and examined by plasmid extraction.

One colony, designated pAV-1, was shown to have an insert of $5.9 \mathrm{~kb}$ and was selected for further investigation. After gel purification and labelling, this sequence was shown to hybridize to the extrachromosomal bands of parental strain DNA in Southern blotting experiments (Fig. 2 , track 16). The insert was digested with a range of restriction endonucleases and analysed using PAGE. Ncil, HaeIII and EcoRI were found to cut at one, two and three sites respectively, and were used for mapping by double digest and end-labelling techniques. The orientation of the insert in the pUC9 vector was established by comparing EcoRI digests of the intact recombinant plasmid and the insert. The resultant map is shown in Fig. 3. Fragment sizes were consistent with data previously obtained for intact chlamydial plasmid digests with HaeIII and EcoRI (unpublished data).

The cloned insert was used as a hybridization probe to attempt to find a suitable enzyme which would linearize the chlamydial plasmid and allow cloning of the complete molecule. Purified plasmid was cleaved in the presence of $\lambda$ bacteriophage DNA as a control for complete digestion, and analysed by Southern blotting. No restriction sites were found for BamHI, PstI, SmaI or XhoI while TaqI cut at multiple sites and, as yet, no linearizing enzyme has been identified.

The size of the intact chlamydial plasmid was estimated to be $7.9 \mathrm{~kb}$ from the insert size $(5.9 \mathrm{~kb})$ plus the four small HindIII bands (Fig. 1). This was consistent with the mobility of a faint band present in undigested chlamydial DNA in agarose gels which we presume to be a linear form of plasmid.

The insert from clone pAV-1 was used to screen a variety of $C$. psittaci isolates for plasmid sequences in dot blot and Southern blot hybridization assays. Fig. 2 shows the results of screening 13 separate avian isolates and the parent strain 725 . Total infected cell DNA was used, so there was little control over the amount of chlamydial DNA in each sample; nevertheless, all isolates showed hybridization with extrachromosomal bands of identical mobility. Weak hybridization observed at the level of chromosomal DNA may indicate a low frequency of integration but may also be due to physical entrapment by the large amount of DNA in this band. The analysis was then extended to include a range of mammalian isolates (Fig. 4) and hybridization was observed with feline pneumonitis, guinea-pig inclusion conjunctivitis and ovine ocular isolates, and also with DNA from C. trachomatis LGV L2 strain. No hybridization 


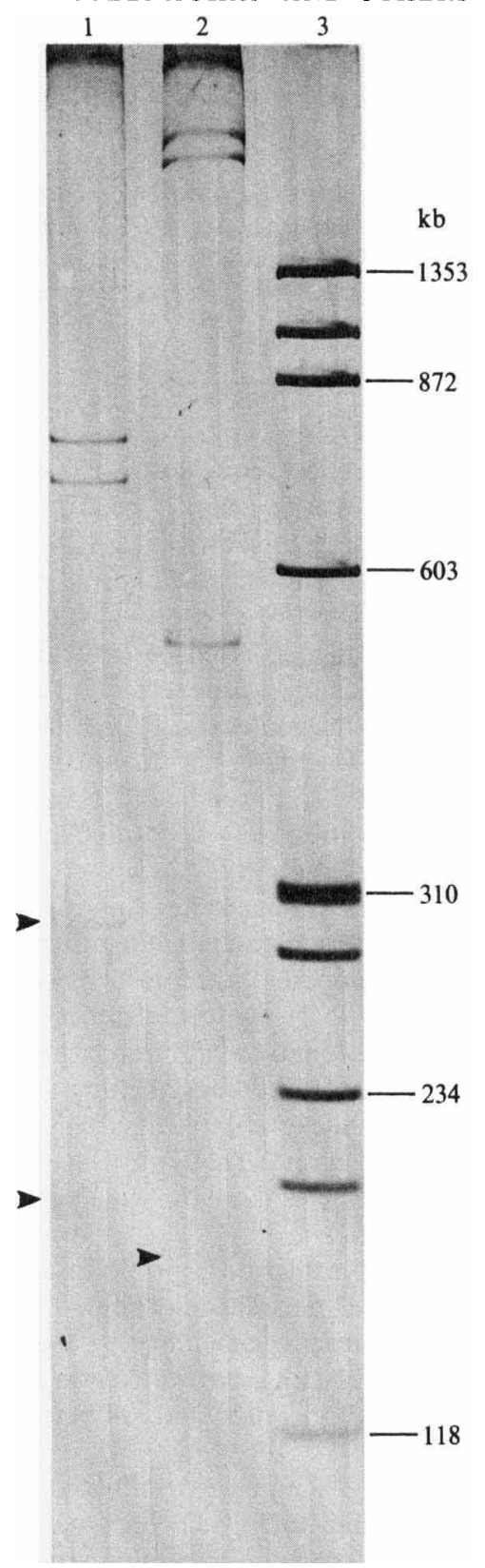

Fig. 1. PAGE of HindIII digests of chlamydial plasmid DNA. Track 1, plasmid from avian strain 725; track 2, plasmid from feline pneumonitis strain; track 3, HaeIII digest of bacteriophage $\phi \times 174$ replicative form DNA. Size standards in base pairs are as indicated. Faintly staining bands are arrowed.

was found with the ovine arthritis strain or with our Cal 10 isolate. When ovine abortion isolates were screened, no hybridization was observed with any of seven isolates as shown by the dot blot analysis in Fig. 5; the other mammalian and avian strains were included as positive controls. Additionally, two abortion isolates of low passage (H574 pass 6 and S507 pass 4) were screened by Southern blotting and were also found to be negative. A previous dot blot experiment showed that our probe did not hybridize with uninfected cellular DNA. The strong hybridization found with the feline pneumonitis strain suggested that this isolate may possess sequences identical to 


7

8

9

10

\section{$-$}

Fig. 2. Southern blot analysis of total undigested DNA from cells infected with avian chlamydial isolates 1-17 (see Table 1 for details). Track 16 is the plasmid donor strain. Origin, chromosomal and plasmid bands as detected by ethidium bromide staining are indicated as $\mathrm{O}, \mathrm{Ch}$ and $\mathrm{P}$, respectively.

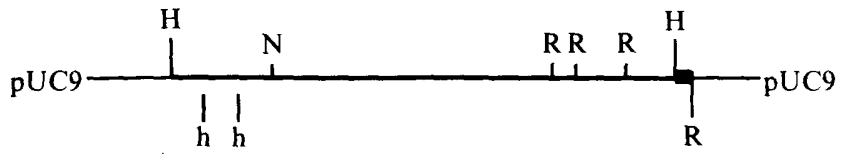

Fig. 3. Restriction site map of the insert of clone pAV-1. H, HindIII; N, NciI; R, EcoRI; h, HaeIII.

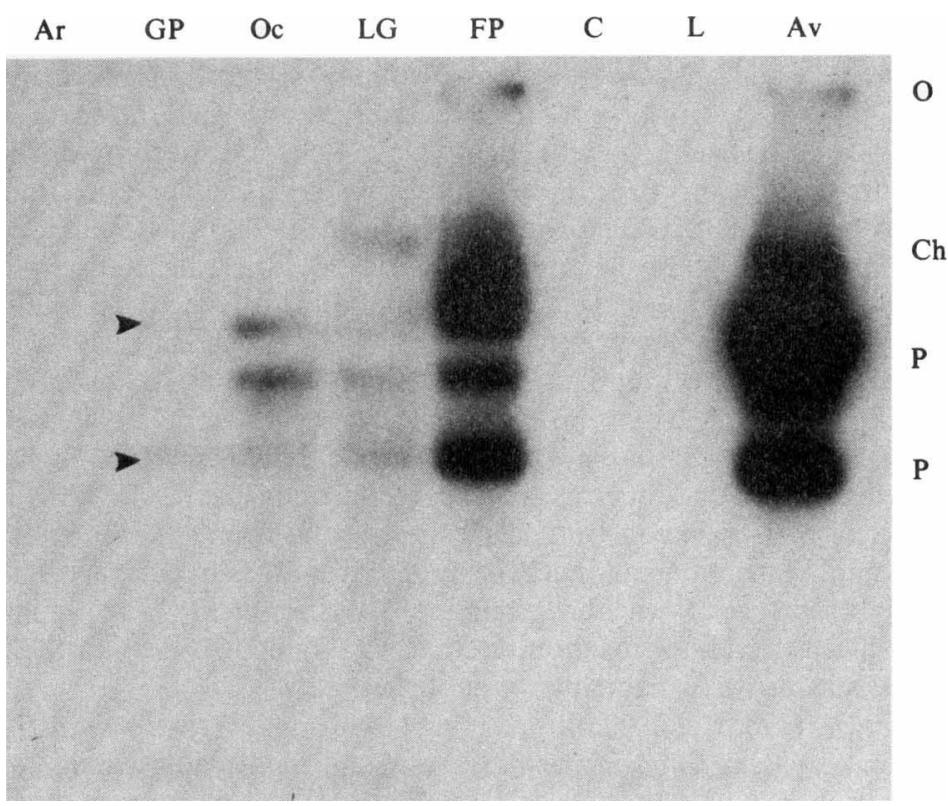

Fig. 4. Southern blot analysis of undigested DNA from purified elementary bodies of various mammalian strains. Ar, ovine arthritis; GP, guinea-pig inclusion conjunctivitis; Oc, ovine conjunctivitis; LG, lymphogranuloma venereum; FP, feline pneumonitis; C, Cal 10; L, $\lambda$ bacteriophage HindIII digested size markers; Av, plasmid donor strain 725 . DNA $(1 \mu \mathrm{g})$ was loaded in each track with the exception of the Oc and GP samples where amounts were too low for quantification, and the 725 strain which received $0.5 \mu \mathrm{g}$. Other abbreviations are as in Fig. 2. 


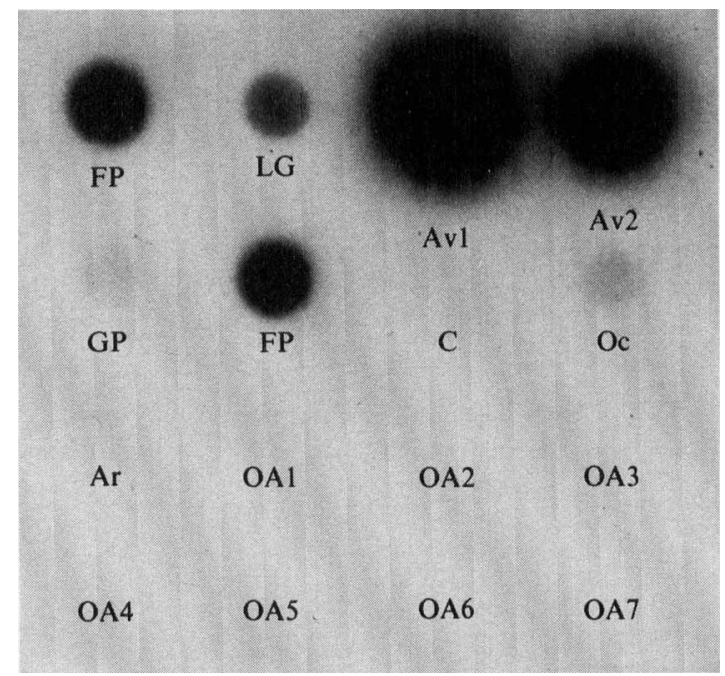

Fig. 5. Dot blot analysis of mammalian strain DNA. Each 'dot' was loaded with $100 \mathrm{ng}$ DNA except for Oc and GP (see Fig. 4). Ovine abortion strains were as follows: OA1, 84/501 (pass 3); OA2, ZC 31; OA3, ZC 26; OA4, ZC 25; OA5, ZC 19; OA6, S26/3 (pass 9); OA7, A22 vaccine strain (pass 25). The other abbreviations used are as in Fig. 4, the avian reference strains Av1 and Av2 representing isolates 725 and 741 respectively.

the avian plasmid. However, when plasmid DNA was purified from this strain by $\mathrm{CsCl} / \mathrm{EB}$ density gradient centrifugation, digested with HindIII and compared with avian plasmid DNA by PAGE, a clearly different profile was obtained as shown in Fig. 1.

\section{DISCUSSION}

The presence of small $6.6 \mathrm{~kb}$ plasmids in chlamydiae was first reported by Lovett et al. (1982) for both C. trachomatis and C. psittaci (meningopneumonitis strain). More recently, Hyypiä et al. (1984) confirmed that the plasmid is present in all 15 serovars of $C$. trachomatis and suggested that this property could be used to detect chlamydiae in clinical specimens. The plasmid from the meningopneumonitis strain (Cal 10, a laboratory strain of uncertain origin and passage history; Francis \& Magill, 1938) was cloned by Joseph et al. (1986) and found to be $6 \cdot 2 \mathrm{~kb}$ in size. The smaller size and the single restriction site for EcoRI distinguishes that plasmid from the avian plasmid we have partially cloned. However, both the Cal 10 plasmid and our avian plasmid share sequence homology with the $C$. trachomatis plasmid which suggests a common ancestry. Plasmids of the same compatibility grouping often share homology at the origin of replication (Broda, 1979). That plasmid DNA may well show more sequence variation than genomic DNA has been suggested by Peterson \& De La Maza (1984) who demonstrated differences in the restriction endonuclease profiles of plasmids from LGV serovars I and II from that of serovar III. We have demonstrated that the plasmid from the feline pneumonitis strain has a clearly different restriction endonuclease profile from that of our parent avian strain, but shows strong hybridization with the cloned $5.9 \mathrm{~kb}$ fragment. The genomic restriction endonuclease profile of the feline pneumonitis strain was found to differ substantially from those of avian or ovine strains (A. J. Herring, unpublished data).

Both Joseph et al. (1986) and Clarke \& Hatt (1986) undertook in vitro transcription and translation of cloned C. trachomatis plasmid DNA and identified plasmid-encoded proteins. Plasmid conservation in a wide variety of strains in both species argues that it confers some selective advantage, but our finding that certain $C$. psittaci strains lack this class of plasmid DNA suggests it is not essential. It is possible that plasmids may be lost in long-term culture as appears to have happened with our strain of $\mathrm{Cal} 10$, but our consistent failure to find plasmid sequences in nine ovine abortion isolates of varying passage level and identical restriction endonuclease profile make it unlikely that any abortion strains have this class of small plasmid. 
Recently, it has been reported that the TWAR strains, which are associated with human respiratory disease, also lack plasmid bands discernible by conventional agarose gel electrophoresis (Campbell et al., 1987). However, the newly introduced pulsed field electrophoretic techniques for larger DNA molecules are ideally suited to reveal if other, larger plasmid forms exist in chlamydiae.

The presence of plasmid in all avian isolates tested from a diversity of species means that clone pAV-1 may well have potential as a diagnostic reagent for the detection of this widespread infection of birds (Grimes, 1985), and in identifying zoonotic episodes.

This work was supported in part by a grant from the Wellcome Foundation.

We thank Neil Inglis for excellent technical assistance and Brian Easter for the photography.

\section{REFERENCES}

Bevan, B. J. \& Bracewell, C. D. (1986). Chlamydiosis in birds in Great Britain. 2. Isolation of C. psittaci from birds sampled between 1976 and 1984. Journal of Hygiene 96, 453-458.

Broda, P. (1979). Plasmids. Oxford \& San Francisco: W. H. Freeman.

Campbell, L. A., Kuo, C.-C. \& Grayston, J. T. (1987). Characterization of the new Chlamydia agent, TWAR, as a unique organism by restriction endonuclease analysis and DNA-DNA hybridization. Journal of Clinical Microbiology 25, 1911-1916.

CLARKE, I. N. \& HATT, C. (1986). In vitro transcription/ translation analysis of cloned plasmid DNA from Chlamydia trachomatis serovar L1. In Chlamydial Infections, pp. 85-88. Edited by D. Oriel, G. Ridgway, J. Schachter, D. Taylor-Robinson \& M. Ward. Cambridge: University Press.

Francis, T. \& Magill, T. P. (1938). An unidentified virus producing acute meningitis and pneumonia in experimental animals. Journal of Experimental Medicine 68, 147-160.

GRIMES, J. E. (1985). Enigmatic psittacine chlamydiosis : results of serotesting and isolating attempts, 1978 through 1983, and considerations for the future. Journal of the American Veterinary and Medical Association 186, 1075-1079.

Grunstein, M. \& Hogness, D. (1975). Colony hybridisation: a method for the isolation of cloned DNAs that contain a specific gene. Proceedings of the National Academy of Sciences of the United States of America 72, 3961-3965.

HANAHAN, D. (1983). Studies on transformation of Escherichia coli with plasmids. Journal of Molecular Biology 166, 557-580.

HerRing, A. J., Inglis, N. F., OJeh, C. K., SNodGRASS, D. R. \& MENZIES, J. D. (1982). Rapid diagnosis of rotavirus infection by direct detection of viral nucleic acid in silver stained polyacrylamide gels. Journal of Clinical Microbiology 16, 473-477.

Hyypï̈, T., Jalava, A., Larsen, S. H., Terho, P. \& HukKanen, V. (1985). Detection of Chlamydia trachomatis in clinical specimens by nucleic acid spot hybridization. Journal of General Microbiology 131, 975-978.

Joseph, T., Nano, F. E., Garon, C. F. \& Caldwell,
H. D. (1986). Molecular characterization of Chlamydia trachomatis and Chlamydia psittaci plasmids. Infection and Immunity 51, 699-703.

Lovett, M., Kuo, C. C., Holmes, K. \& Falkow, S. (1980). Plasmids of the genus Chlamydia. In Current Chemotherapy and Infectious Disease 2, pp. 1250 1252. Edited by J. D. Nelson \& C. Grassi, Washington, DC: American Society for Microbiology.

Maniatis, T., Fritsch, E. F. \& Sambrook, J. (1982). Molecular Cloning: a Laboratory Manual. Cold Spring Harbor, New York: Cold Spring Harbor Laboratory.

McClenaghan, M., Herring, A. J. \& Aitken, I. D. (1984). Comparison of Chlamydia psittaci isolates by restriction endonuclease analysis. Infection and Immunity 45, 384-389.

Perez-Martinez, J. A. \& Storz, J. (1985). Antigenic diversity of Chlamydia psittaci of mammalian origin determined by microimmunofluorescene. Infection and Immunity 50, 905-910.

Peterson, E. M. \& De La MazA, L. M. (1983). Characterization of Chlamydia DNA by restriction endonuclease cleavage. Infection and Immunity 41, 604-608.

RaAfat El-Gewely, M. \& Helling, R. B. (1980). Preparative separation of DNA-ethidium bromide complexes by zonal density gradient centrifugation. Analytical Biochemistry 102, 423-428.

Rigby, P. W. J., DieckmanN, M., Rhodes, C. \& BERG, P. (1977). Labeling deoxyribonucleic acid to high specific activity in vitro by nick translation with DNA polymerase I. Journal of Molecular Biology 113, 237-251.

Smith, H. O. \& Bernsteil, M. L. (1976). A simple method for DNA restriction site mapping. Nucleic Acids Research 3, 2387-2398.

Wenman, W. M. \& LovetT, M. A. (1982). Expression in $E$. coli of Chlamydia trachomatis antigen recognized during human infection. Nature, London 296, 68-70.

Yanisch-Perron, C., Vieira, J. \& Messing, J. (1985). Improved M13 phage cloning vectors and host strains. Nucleotide sequences of the M13mp18 and pUC19 vectors. Gene 33, 103-119. 